\title{
Effects of dexmedetomidine post-treatment on BDNF and VEGF expression following cerebral ischemia/reperfusion injury in rats
}

\author{
ZHENG-CHEN LI ${ }^{1,2}$, YING-PING JIA ${ }^{2}$, YUAN WANG ${ }^{2}$, JIN-LIAN QI ${ }^{2}$ and XUE-PING HAN ${ }^{1}$ \\ ${ }^{1}$ Department of Anesthesia, The First Affiliated Hospital of Zhengzhou University, Zhengzhou, Henan 450052; \\ ${ }^{2}$ Department of Anesthesia, Zhengzhou Children's Hospital, Zhengzhou, Henan 450053, P.R. China
}

Received August 18, 2016; Accepted October 25, 2017

DOI: $10.3892 / \mathrm{mmr} .2018 .8597$

\begin{abstract}
Brain-derived neurotrophic factor (BDNF) and vascular endothelial growth factor (VEGF) serves a significant role in neural protection by activating the phosphatidylinositol 3-kinase (PI3K)/Akt signaling pathway, which also was associated with the neuroprotective the treatment with dexmedetomidine (DEX). The present study aimed to further explore whether treatment with DEX post-IR increased the expression level of BDNF and VEGF in the rat brain. A total of 30 healthy, clean male Wistar rats were randomly divided into 3 experimental groups: Control group, ischemia/reperfusion (I/R) group and DEX treatment group. Subsequently, BDNF and VEGF mRNA and protein expression levels were analyzed. The results indicated that the mRNA expression levels of BDNF and VEGF were higher in the I/R and DEX groups compared with expression levels in the Control group at $6 \mathrm{~h}$ and 1 day post-treatment; the levels of BNDF mRNA expression were higher in the DEX group compared with the I/R group. The levels of BDNF and VEGF protein expression in the I/R and DEX groups were also significantly higher compared with those in the Control group. I/R surgery significantly increased the expression of BDNF and VEGF protein DEX group at $6 \mathrm{~h}$, day 1 and day 3 compared with expression levels in the I/R group. Results from the present study indicated that post-surgical treatment with DEX may increase the expression of BDNF and VEGF following I/R, which may serve a role in nerve protection.
\end{abstract}

\section{Introduction}

Transient ischemic attack may result in damage to local brain tissues and decreased brain function (1). The sequelae of cerebral ischemia may lead to serious physical disabilities in

Correspondence to: Professor Xue-Ping Han, Department of Anesthesia, The First Affiliated Hospital of Zhengzhou University, 1 Jianshedong Road, Zhengzhou, Henan 450052, P.R. China

E-mail: hanxueping195812@sina.com

Key words: dexmedetomidine, brain-derived neurotrophic factor, vascular endothelial growth factor, cerebral ischemia-reperfusion patients, which may exert a great influence on patient quality of life and bring heavy economic burden on society and family (2). Historically, treatment of ischemic brain injury was focused on reducing neuronal death; however, an increasing number of studies have suggested that angiogenesis following cerebral ischemia may serve an important role in neurological function reconstruction and the repair process $(3,4)$.

Dexmedetomidine (DEX) is a specific and short-acting agonist of the $\alpha 2$ adrenergic receptor (5); it is a potent drug that may produce severe physiological changes. A previous study confirmed that intrathecal administration of DEX prolonged motor and sensory block, enhanced hemodynamic stability and reduced the requirement for rescue analgesics in $24 \mathrm{~h} \mathrm{(6).}$

Brain-derived neurotrophic factor (BDNF) is the most abundant neurotrophic factor in brain tissue and serves a role in inhibiting apoptosis, promoting neuronal survival, activating neural stem cells (NSCs) following ischemic brain injury, and regulating neural plasticity. BDNF belongs to a class of proteins that are synthesized by brain tissues and are widely expressed in the central nervous system (CNS); it serves a significant role in CNS development and neuronal growth and differentiation (7). In addition, BDNF has been reported to prevent neuronal death, improve pathology and facilitate the regeneration and differentiation of damaged neurons (8). Previous studies have demonstrated that the administration of BDNF following brain artery occlusion improved the survival rate of neurons and decreased the volume of cerebral infarction, and it was revealed that the expression level of BDNF was positively correlated with the ability of local neurons to tolerate ischemic injury $(9,10)$. However, further studies are required to investigate whether DEX post-treatment promoted the survival and repair of the neurons by increasing BDNF expression levels.

Vascular endothelial growth factor (VEGF) belongs to a class of heparin-binding proteins that have a highly conserved structure and they function to promote angiogenesis, maintain vascular permeability and endothelial proliferation (11). Previous studies have reported that VEGF was widely expressed in the brain tissues of adult rats, and this expression was increased following brain ischemia $(12,13)$. It may be possible that VEGF expression promotes the maturation of newborn neurons and the generation of the striatum nerve in adult rats by inhibiting potassium channel activity, which may contribute to neural protection. 
A number of studies have confirmed that BDNF expression promoted the survival of neurons and upregulated the release of neurotransmitters by combining with tropomyosin-related kinase B (TrkB) and subsequently activating the phosphatidylinositol 3-kinase (PI3K)/Akt (also known as protein kinase B) signaling pathway, which served a significant role in neural protection (14-16). In addition, VEGF was revealed to regulate the PI3K/Akt signaling to inhibit the activity of Caspase-3 and to regulate voltage-gated potassium channels, thereby, reducing ischemia-induced neuronal death. DEX post-treatment was reported to be beneficial to neuroprotection by activating PI3K/Akt signaling pathway (17). The present study aimed to further explore whether the post-treatment with DEX increased the expression levels of BDNF and VEGF following ischemia/reperfusion (I/R) injury. The I/R injury and the morbidity rate, was also described and investigated the association between BDNF and VEGF. These results may provide the scientific basis for elucidating the mechanism of post-treatment with DEX on I/R injury.

\section{Materials and methods}

Experimental design. A total of 30 healthy, clean male Wistar rats (6 weeks old, 160-180 g) were randomly divided into three experimental groups (10 rats/group) under the circumstance of SPF level as follows: i) The Control group, which received surgical procedure to expose the external carotid artery, without ischemia induction; ii) the I/R group, which received an intraperitoneal injection of sterile saline $(1 \mathrm{ml})$ in reperfusion $60 \mathrm{~min}$ following brain ischemia surgery (18); iii) the DEX group, which received an intraperitoneal injection of DEX (50 $\mu \mathrm{g} / \mathrm{kg}$; Jinzhou Jiutai Pharmaceutical Co., Ltd, Liaoning, China) in reperfusion 60 min following brain ischemia surgery.

Breeding environment was as follows: 12-h light and dark cycle, temperature in $18-26^{\circ} \mathrm{C}$, relative humidity in $40-70 \%$, and ventilation for 8-12 times/h. The water was supplied by a water bottle and changed for three times a week. Sufficient food was supplied. The study protocol was approved by The Institutional Review Board of the First Affiliated Hospital of Zhengzhou University (Henan, China). All animal handling procedures were carried out in accordance with the protocols of the animal care guidelines of the Institutional Animal Care Committee.

Rats in each group were anesthetized with $10 \%$ chloral hydrate at 6 h, 1 day, 3 days and 7 days following I/R surgery, and immediately decapitated 2, 2, 3 and 3 rats at the respective time points. Whole brain tissue samples were extracted and placed on ice-cold glass. The ischemic penumbra in the parietal cortex was quickly separated and placed into vials; an example of the typical histology of cerebral tissues is provided in Fig. 1. Brain tissues were frozen in liquid nitrogen and stored at $-70^{\circ} \mathrm{C}$ until use.

BDNF and VEGF mRNA expression analysis. Total RNA was extracted from the $200 \mathrm{mg}$ brain samples. The RNA concentration and purity were detected using a Nanodrop 2000 (Thermo Fisher Scientific, Inc., Wilmington, DE, USA). Total RNA was reverse transcribed into cDNA using the M-MLV Reverse Transcription kit (Kangweishiji, Beijing, China; cat no. 20219) at $37^{\circ} \mathrm{C}$ for $10 \mathrm{~min}$ according to the manufacturer's protocol. Primers were designed to detect BDNF and VEGF mRNA by polymerase chain reaction (PCR); a list of primer sequences is provided in Table $\mathrm{I}$. The $\mathrm{Cq}$ value for each gene was measured, and the $\Delta \Delta \mathrm{Cq}$ values were determined from the average of three parallel experiments. The values were calculated as follows: $\Delta \mathrm{Cq}=\mathrm{Cq}_{\text {(Target Gene) }}-\mathrm{Cq}_{\text {(Reference gene); }}$; $\Delta \Delta \mathrm{Cq}=\Delta \mathrm{Cq}_{\text {(sample) }}-\Delta \mathrm{Cq}_{\text {(control). }}$ The relative expression level of target genes was calculated using the $2^{-\Delta \Delta \mathrm{Cq}}$ method (19). The relative expression level of the control $\left(\beta\right.$-actin) was $2^{0}=1$. The qPCR reactions contained: $10 \mu \mathrm{l} 2 \mathrm{X}$ SYBR Fast qPCR mix; $0.8 \mu \mathrm{l}$ PCR forward/ reverse Primers (10 mM); $0.4 \mu 1$ 50X ROX reference dye II; $2 \mu \mathrm{l}$ cDNA template. The reaction parameters were as follows: Initial denaturation at $95^{\circ} \mathrm{C}$ for $30 \mathrm{sec}$, followed by 40 cycles of $95^{\circ} \mathrm{C}$ for $3 \mathrm{sec}$ and $58^{\circ} \mathrm{C}$ for $30 \mathrm{sec}$. PCR products were detected by $1.5 \%$ agarose gel electrophoresis stained by ethidium bromide. $\beta$-actin was used as the internal reference and for densitometric analysis by Quantity One 4.62 (Bio-Rad Laboratories, Inc., Hercules, CA, USA). Every experiment repeated three times.

BDNF and VEGF protein expression analysis. Lysis buffer (C1053+; Beijing Pulilai Gene Technology, Co., Ltd., Beijing, China) were added to $200 \mu \mathrm{g}$ brain samples. Following $30 \mathrm{~min}$ of lysis, the cells were centrifuged at 11,180 x g for $20 \mathrm{~min}$ at $4^{\circ} \mathrm{C}$. The supernatant was collected and the total protein was extracted. Total protein concentration was quantified by the bicinchoninic acid method. Proteins were separated by SDS-PAGE and transferred to a polyvinylidene difluoride membrane (Pierce; Thermo Fisher Scientific, Inc.). A total of $\sim 20 \mu \mathrm{l}$ protein was loaded per lane. Following blocking for $2 \mathrm{~h}$ at $37^{\circ} \mathrm{C}$, the primary (Abcam, Cambridge, UK; cat. no. ab108319 for BDNF; cat. no. ab32152) and incubated at room temperature for $2 \mathrm{~h}$. The membrane was rinsed three times (5-10 min each) with TBST and incubated with horseradish peroxidase-labeled secondary antibody (Wuhan BOSHIDE Biological engineering Co. Ltd., Wuhan, China; cat. no. SV0002), which was diluted $(1: 10,000)$ with TBST containing $0.05 \%$ of skim milk and incubated at room temperature for $2 \mathrm{~h}$. The membrane was rinsed three times with TBST (5-10 min) and the experimental results were preserved by exposure and photographic processing. The optical density of the immunoblotting zone was measured by laser light density scanner. Quantity One software version 4.62 (Bio-Rad Laboratories, Inc.) was used for densitometric analysis, and the semi-quantitative values of target protein/reference protein were used for statistical analysis (20). Every experiment was repeated three times.

Statistical analysis. Statistical analysis was performed with SPSS 13.0 statistical software (SPSS, Inc., Chicago, IL, USA). All experimental results are presented as the mean \pm standard deviation. Multiple groups were compared by analysis of variance followed by Student-Newman-Keuls the post hoc test. $\mathrm{P}<0.05$ was considered to indicate a statistically significant difference.

\section{Results}

BDNF and VEGF mRNA expression. The mRNA expression levels of BDNF in cortical ischemic penumbra of rats in 


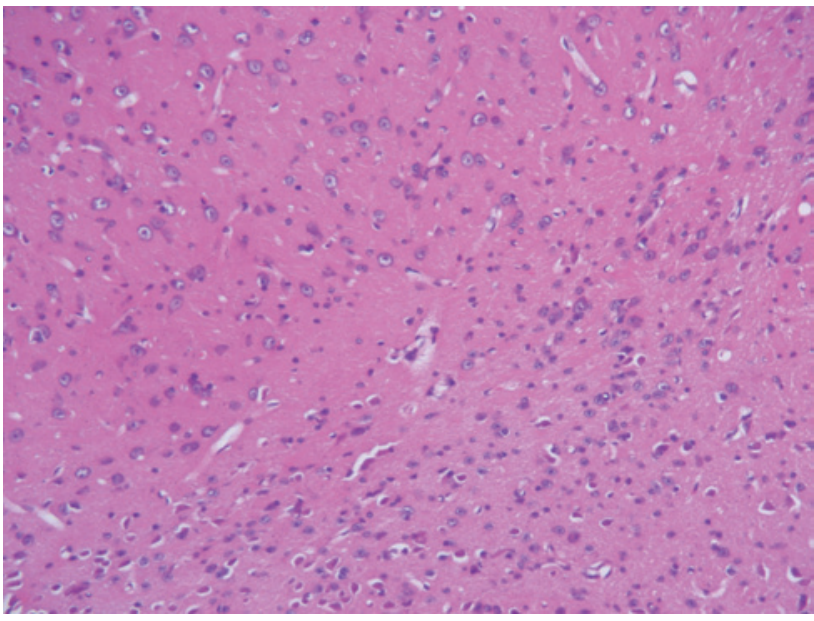

Figure 1. Typical histology of cerebral tissues resected from Control group of rats.

each group were examined (Fig. 2). The results indicated that BDNF mRNA expression levels were higher in both the $\mathrm{I} / \mathrm{R}$ and DEX groups at $6 \mathrm{~h}$ and 1 day post-surgery compared with the expression level in the Control group $(\mathrm{P}<0.05)$. The levels of BNDF mRNA expression were higher in the DEX-treated group at $6 \mathrm{~h}$ and 1 day post-surgery compared with the levels of expression in the $I / R$ group $(\mathrm{P}<0.05)$. Compared with the Control group, BDNF mRNA expression in the I/R and DEX groups increased at $6 \mathrm{~h}$ post-surgery, reached the peak on day 1, decreased Day 3 and reached Control group levels at day 7. Similar expression levels and a similar trend over time were observed for VEGF mRNA in the three groups (Fig. 3). However, the significant differences among the three groups were observed at Day 3 for VEGF.

BDNF and VEGF protein expression. The protein expression levels of BDNF were detected in cortical ischemic penumbra tissues of rats in each group (Fig. 4). The result demonstrated that the expression levels of BDNF proteins were significantly higher in the I/R and DEX groups compared with protein expression levels in the Control group at $6 \mathrm{~h}, 1$ day and 3 days post-surgery $(\mathrm{P}<0.05)$. Similar to the miRNA expression levels, the protein expression levels of BDNF in the I/R and DEX groups increased at $6 \mathrm{~h}$, reached the peak in day 1 , and declined at day 3 , and reached a similar level of expression as the Control group at day 7. Compared with the I/R group, rats in the DEX group exhibited a significantly higher expression level of BDNF protein at $6 \mathrm{~h}, 1$ day and 3 days following I/R surgery $(\mathrm{P}<0.05)$. However, there was no significant difference between two groups at day 7 ( $\mathrm{P}>0.05)$.

The expression levels of VEGF proteins in cortical ischemic penumbra of rats in the three groups were also examined (Fig. 5). The expression levels of VEGF protein in the I/R and DEX groups increased at $6 \mathrm{~h}$ post-surgery, reached a peak at day 1, declined at Day 3 reaching similar levels as the Control group at day 7. The expression levels of VEGF protein in the $\mathrm{I} / \mathrm{R}$ and DEX groups were significantly higher compared with the Control group at $6 \mathrm{~h}, 1$ day and 3 days $(\mathrm{P}<0.05)$. Compared with the I/R group, DEX-treated rats exhibited a significantly
Table I. List of primer sequences used for reverse transcriptionpolymerase chain reaction.

\begin{tabular}{llc}
\hline Gene & \multicolumn{1}{c}{ Sequence (5'-3') } & $\begin{array}{c}\text { Expected } \\
\text { size (bp) }\end{array}$ \\
\hline BDNF & $\begin{array}{l}\text { F: CGTGGGGAGCTGAGCGTGTG } \\
\text { R: GCCCCTGCAGCCTTCCTTC }\end{array}$ & 192 \\
\multirow{2}{*}{ VEGF } & $\begin{array}{l}\text { F: GCCGCAGGAGGCAAACCGAT } \\
\text { R:actin }\end{array}$ & 242 \\
& $\begin{array}{l}\text { R: TGGCGGGCTCCTCTCCCTT } \\
\text { R: GCTGTCACTGGCCTCGCTG }\end{array}$ & 250 \\
& RTCACCGTTCC & \\
\hline
\end{tabular}

BDNF, brain-derived neurotrophic factor; F, forward; R, reverse; VEGF, vascular endothelial growth factor.

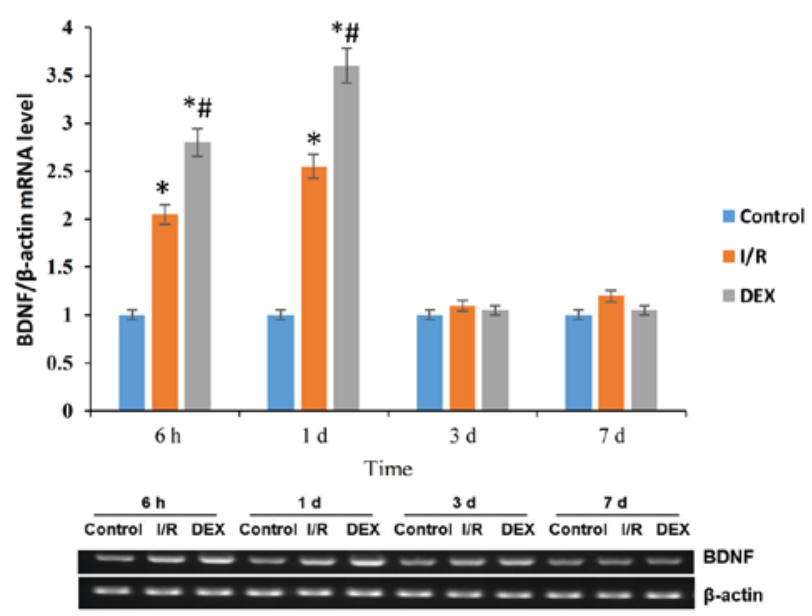

Figure 2. Expression levels of BDNF mRNA in the three groups were detected by reverse transcription-polymerase chain reaction in the three groups. BDNF, brain-derived neurotrophic factor; DEX, dexmedetomidine; $\mathrm{I} / \mathrm{R}$, ischemia/reperfusion. ${ }^{\mathrm{P}} \mathrm{P}<0.05$ vs. Control; ${ }^{*} \mathrm{P}<0.05$ vs. I/R. Every experiment was repeated three times.

higher expression level of BDNF protein at $6 \mathrm{~h}, 1$ day and 3 days post-I/R surgery $(\mathrm{P}<0.05)$.

\section{Discussion}

BDNF is an important member of the family of neurotrophic factors and is widely expressed in the brain cells of adult mammals. BDNF combines with TrkB and activates intracellular signaling pathways, such as mitogen activated protein kinase (MAPK)/extracellular signal-regulated kinase, phospholipase $\mathrm{C} \gamma(\mathrm{PLC} \gamma)$ and PI3K $(21,22)$. BDNF serves an important role in promoting the survival and functional repair of neuronal cells by regulating these signaling pathways. In addition, BDNF is essential in neural transmission and in activity-dependent plasticity (23). Long-term potentiation is the major form of synaptic plasticity, which is induced and maintained by BDNF (24). BDNF was previously reported to upregulate the depolarization of isolated cortical and hippocampal neurons, which induced the release of glutamic acid (25-27). Therefore, BDNF may have a vital effect on the survival and functional recovery of neurons in the CNS. In the 


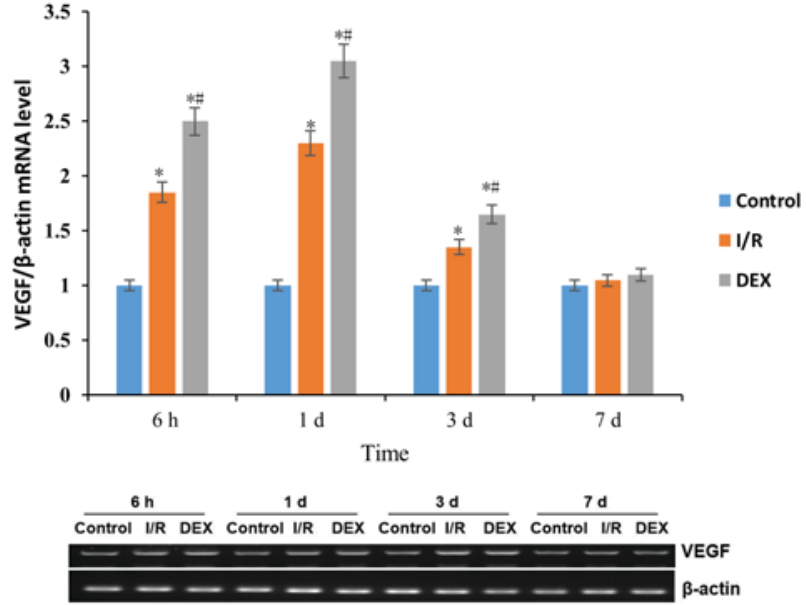

Figure 3. Expression levels of VEGF mRNA in the three groups were detected by reverse transcription-polymerase chain reaction in the three groups. DEX, dexmedetomidine, brain-derived neurotrophic factor; I/R, ischemia-reperfusion; VEGF, vascular endothelial growth factor. ${ }^{*} \mathrm{P}<0.05$ vs. Control; ${ }^{~} \mathrm{P}<0.05$ vs. I/R. Every experiment was repeated three times.

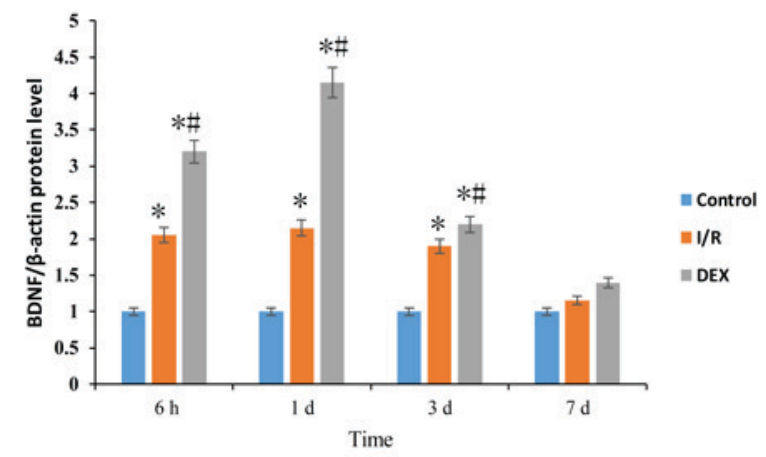

Control I/R DEX Control I/R DEX

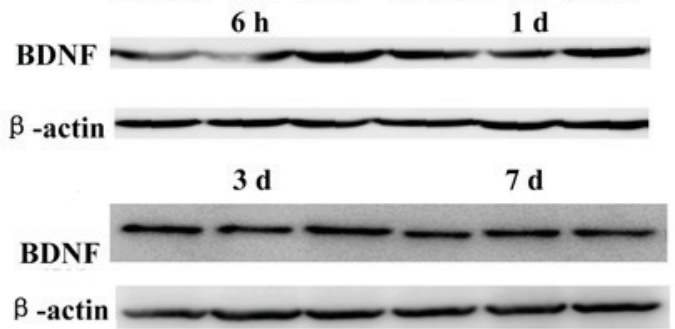

Figure 4. Expression levels of BDNF protein in the three groups were detected by western blot analysis in the three groups. BDNF, brain-derived neurotrophic factor; DEX, dexmedetomidine; I/R, ischemia/reperfusion ${ }^{*} \mathrm{P}<0.05$ vs. Control; ${ }^{\#} \mathrm{P}<0.05$ vs. I/R. Every experiment was repeated three times.

present study, cerebral ischemia led to the increased expression of BDNF mRNA and protein, which is an endogenous protective mechanism of the body. Compared to the $\mathrm{I} / \mathrm{R}$ group, DEX treatment post-I/R surgery upregulated the expression levels of BDNF, which suggested that post-treatment with DEX may have a cerebral protective effect by increasing the expression of BDNF, thus promoting the survival of neurons and the activation of NSC. However, these results also suggested that the DEX-induced increase in BDNF expression may only be maintained for three days post-reperfusion. This may be due to the early expression of the protective protein BDNF. Therefore, the effects of single DEX post-treatment may by

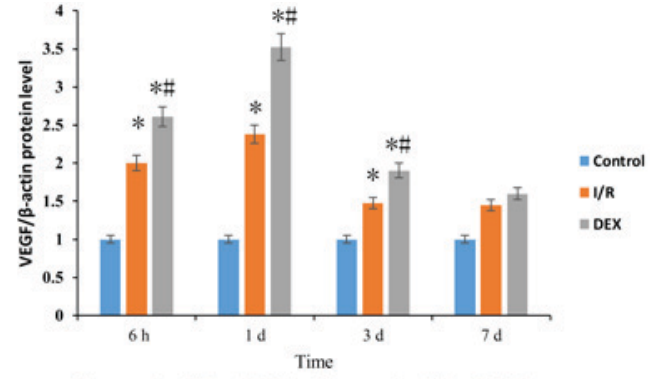

Control I/R DEX Control I/R DEX

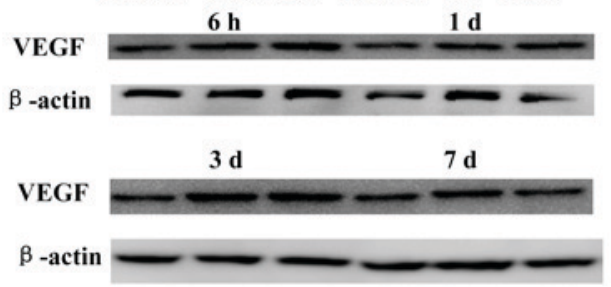

Figure 5. Expression levels of VEGF protein in the three groups were detected by western blot analysis in the three groups. DEX, dexmedetomidine, brain-derived neurotrophic factor; I/R, ischemia-reperfusion; VEGF, vascular endothelial growth factor. ${ }^{*} \mathrm{P}<0.05$ vs. Control; ${ }^{\#} \mathrm{P}<0.05$ vs. I/R. Every experiment was repeated three times.

limited. Future studies should consider conducting multiple DEX treatments to maintain these effects.

VEGF is a highly conserved heparin-binding protein. In ischemic brain tissues, the expression of endogenous VEGF was upregulated, which was reported to have a protective effect on the brain tissue during the pathological and physiological processes induced by ischemia (28). Previous in vitro and in vivo studies have demonstrated that the administration of VEGF antisense oligonucleotides increased the sensitivity to ischemic and anoxic injuries in brain tissue or neurons, which led to an increase of the number of apoptotic cells and cerebral infarction volume, and subsequently reduced the survival rate of nerve cells, aggravating the nerve injury caused by ischemia (29-31). Results from the present study demonstrated that DEX-treatment post-I/R surgery significantly increased the expression levels of VEGF mRNA and protein compared with rats in the untreated I/R group. These data suggested that post-treatment with DEX may promote angiogenesis and maintain vascular permeability by increasing the expression levels of VEGF, thereby promoting the maturation of new neurons and the generation of striatal neurons.

Cerebral ischemia may lead to the activation of static NSC in the injured brain tissue, which may be beneficial to repairing the structure and function of damaged brain tissue. Proliferation of neural cells requires angiogenesis to provide nutrition, and the formation of new blood vessels requires the proliferation of endothelial cells (32). BDNF and VEGF serve essential roles in the activation of NSC, the reduction of apoptosis and the promotion of angiogenesis. The present study demonstrated that DEX post-treatment significantly increased BDNF and VEGF expression levels in rats following $\mathrm{I} / \mathrm{R}$ injury in the cortical ischemic penumbra. However, the mechanism of neuronal proliferation and angiogenesis require further investigation. The results indicated that post-treatment with DEX increased the expression levels of BDNF and VEGF, which may serve a role in nerve protection. 


\section{Acknowledgements}

The present study was supported by The Fundamental and Advanced Research from Science and Technology Agency of Henan Province (grant no. 122300410407).

\section{References}

1. Gaur V and Kumar A: Effect of nonselective and selective COX-2 inhibitors on memory dysfunction, glutathione system, and tumor necrosis factor alpha level against cerebral ischemia reperfusion injury. Drug Chem Toxicol 35: 218-224, 2012.

2. Fróes KS, Valdés MT, Lopes Dde P and Silva CE: Factors associated with health-related quality of life for adults with stroke sequelae. Arq Neuropsiquiatr 69: 371-376, 2011.

3. Wang J, Wei D and Xie Y: Effects of electroacupuncture on angiogenesis after ischemia and reperfusion. Chin J Phys Med Rehabilit 37: 503-507, 2015.

4. Vegetarianism: Addition by subtraction. An increasing number of studies are finding health benefits from a low- or no-meat diet. Harv Health Lett 29: 6, 2004.

5. Khan ZP, Ferguson CN and Jones RM: Alpha-2 and imidazoline receptor agonists. Their pharmacology and therapeutic role. Anaesthesia 54: 146-165, 1999.

6. Mahendru V, Tewari A, Katyal S, Grewal A, Singh MR and Katyal R: A comparison of intrathecal dexmedetomidine, clonidine, and fentanyl as adjuvants to hyperbaric bupivacaine for lower limb surgery: A double blind controlled study. J Anaesthesiol Clin Pharmacol 29: 496-502, 2013.

7. Kowiański P, Lietzau G, Czuba E, Waśkow M, Steliga A and Moryś J: BDNF: A key factor with multipotent impact on brain signaling and synaptic plasticity. Cell Mol Neurobiol: Jun 16 , 2017 (Epub ahead of print)

8. Miao JT, Li ZY, Lei GS, et al: Expression of NGF and BDNF after amyloid- $\beta$ protein injected into meynert nucleus in rat. Chin J Neuroimmunol Neurol 2: 67-70, 2003.

9. Cascante A,KlumS, Biswas M,Antolin-Fontes B,Barnabé-HeiderF and Hermanson O: Gene-specific methylation control of H3K9 and H3K36 on neurotrophic BDNF versus astroglial GFAP genes by KDM4A/C regulates neural stem cell differentiation. J Mol Biol 426: 3467-3477, 2014.

10. $\mathrm{Xu} \mathrm{H}$ and Heilshorn SC: Microfluidic investigation of BDNF-enhanced neural stem cell chemotaxis in CXCL12 gradients. Small 9: 585-595, 2013.

11. Brown LF, Detmar M, Claffey K, Nagy JA, Feng D, Dvorak AM and Dvorak HF: Vascular permeability factor/vascular endothelial growth factor: A multifunctional angiogenic cytokine. EXS 79: 233-269, 1997.

12. Jin K, Mao XO, Batteur SP, McEachron E, Leahy A and Greenberg DA: Caspase-3 and the regulation of hypoxic neuronal death by vascular endothelial growth factor. Neuroscience 108 : 351-358, 2001

13. Neufeld G, Cohen T, Gengrinovitch S and Poltorak Z: Vascular endothelial growth factor (VEGF) and its receptors. FASEB J 13: 9-22, 1999 .

14. Chang J, Yao X, Zou H, Wang L, Lu Y, Zhang Q and Zhao H: $\mathrm{BDNF} / \mathrm{PI} 3 \mathrm{~K} / \mathrm{Akt}$ and Nogo-A/RhoA/ROCK signaling pathways contribute to neurorestorative effect of Houshiheisan against cerebral ischemia injury in rats. J Ethnopharmacol 194: 1032-1042, 2016.
15. Luo L, Liu XL, Li J, Mu RH, Liu Q, Yi LT and Geng D: Macranthol promotes hippocampal neuronal proliferation in mice via BDNF-TrkB-PI3K/Akt signaling pathway. Eur J Pharmacol 762: 357-363, 2015

16. Wang W, Lu Y, Xue Z, Li C, Wang C, Zhao X, Zhang J, Wei X, Chen X, Cui W, et al: Rapid-acting antidepressant-like effects of acetyl-1-carnitine mediated by PI3K/AKT/BDNF/VGF signaling pathway in mice. Neuroscience 285: 281-291, 2015.

17. Cheng XY, Gu XY, Gao Q, Zong QF, Li XH and Zhang Y: Effects of dexmedetomidine postconditioning on myocardial ischemia and the role of the PI3K/Akt-dependent signaling pathway in reperfusion injury. Mol Med Rep 14: 797-803, 2016.

18. Yu PL, Sui LM, Han S, Zhao HY, Jiang J and Li JF: Evaluation of middle cerebral artery occlusion induced focal cerebral ischemia model in mice. J Cap Med Univ 31: 586-590, 2010.

19. Livak KJ and Schmittgen TD: Analysis of relative gene expression data using real-time quantitative PCR and the 2(-Delta Delta $\mathrm{C}(\mathrm{T})$ ) method. Methods 25: 402-408, 2001.

20. Siegel EM, Riggs BM, Delmas AL, Koch A, Hakam A and Brown KD: Quantitative DNA methylation analysis of candidate genes in cervical cancer. PLoS One 10: e0122495, 2015.

21. Numakawa T, Richards M, Adachi N, Kishi S, Kunugi $H$ and Hashido K: MicroRNA function and neurotrophin BDNF. Neurochem Int 59: 551-558, 2011.

22. Soumen R, Johnston AH, Moin ST, Dudas J, Newman TA, Hausott B, Schrott-Fischer A and Glueckert R: Activation of TrkB receptors by NGF $\beta$ mimetic peptide conjugated polymersome nanoparticles. Nanomedicine 8: 271-274, 2012.

23. Lepack AE, Fuchikami M, Dwyer JM, Banasr M and Duman RS BDNF release is required for the behavioral actions of ketamine. Int J Neuropsychopharmacol 18: pii: pyu033, 2014.

24. Patterson SL, Abel T, Deuel TA, Martin KC, Rose JC and Kandel ER: Recombinant BDNF rescues deficits in basal synaptic transmission and hippocampal LTP in BDNF knockout mice. Neuron 16: 1137-1145, 1996.

25. Li J, Che YQ, Kang ZW and Lin Q: The dynamic expression of Nogo-A mRNA of cerebellar cortex after the infarction of rats middle cerebral artery supply area. Chin J Hemorheol 20: 246-2249, 2010.

26. Li YP, Guo RF, Li YC and Li HY: The expression and its significance of brain-derived neurotrophic factor in different hippocampal subfields after focal cerebral ischemia in rats. Chin J Gerontol 24: 1180-1182, 2004.

27. Wang ZJ, Lu BX and Ji Z: Effect on Fluoxetine pretreatment hippocampus BDNF and the BCL-2 expression in ischemia-reperfusion rats. Chin J Minima Invas Neruosurg 10: 414-416, 2005.

28. Zhang HL and Li SY: Progress on the Hif-1, vascular endothelial growth facor and cerebral ischemia tolerance. J Clin Neurol 28: 69-70, 2015.

29. Foxton RH, Finkelstein A, Vijay S, Dahlmann-Noor A, Khaw PT Morgan JE, Shima DT and Ng YS: VEGF-A is necessary and sufficient for retinal neuroprotection in models of experimental glaucoma. Am J Pathol 182: 1379-1390, 2013.

30. Winther H, Ahmed A and Dantzer V: Immunohistochemical localization of vascular endothelial growth factor (VEGF) and its two specific receptors, Flt-1 and KDR, in the porcine placenta and non-pregnant uterus. Placenta 20: 35-43, 1999.

31. Xia DY, Li W, Qian HR, Yao S, Liu JG and Qi XK: Ischemia preconditioning is neuroprotective in a rat cerebral ischemic injury model through autophagy activation and apoptosis inhibition. Braz J Med Biol Res 46: 580-588, 2013.

32. Liu YP, Lang BT, Baskaya MK, Dempsey RJ and Vemuganti R: The potential of neural stem cells to repair stroke-induced brain damage. Acta Neuropathol 117: 469-480, 2009. 